\title{
Verzeichnis der Fundorte
}

unter Angabe der Briefnummern

Die meisten der im vorliegenden Band gedruckten Briefe sind in der Leipziger Universitätsbibliothek (UB), Ms 0342, überliefert.

Weitere Briefe entstammen den folgenden Einrichtungen bzw. Veröffentlichungen:

Altenburg, Thüringisches Staatsarchiv: Nr. 7, 36, 131, 135, 147, 161, 187

Bologna, Accademia delle Scienze: Nr. 31

Gdańsk, Biblioteka Główna Politechniki: Nr. 125

Kraków, Biblioteka Jagiellońska: Nr. 62

Venedig, Biblioteca Stampalia: Nr. 29, 112

Ehrenmaal Manteuffel: Nr. 54

Gottsched: Neueste Gedichte auf verschiedene Vorfälle: Nr. 189

L. A. V. Gottsched, Kleinere Gedichte: Nr. 197a, 199a, 207

Runckel 2: Nr. 115, 197b, 199b

Vergnügte Abendstunden: Nr. 19 
